American J. of Engineering and Applied Sciences 1 (4): 241-247, 2008

ISSN 1941-7020

(C) 2008 Science Publications

\title{
Relational GIS and Remote Sensing Database System for Al-Salt Area, Jordan
}

\author{
Eyad H.R. Fadda, Maher Kakish and Emad Jalal Akawwi \\ Department of Surveying and Geomatics Engineering, \\ Faculty of Engineering, Al-Balqa’ Applied University, Al-Salt, 19117, Jordan
}

\begin{abstract}
Due to the importance of database systems, integration between two Geomatics sciences, GIS and Remote Sensing has been made in order to support and serve various sectors in Jordan. GIS has been used to create layers that can show decision makers in a simple, easy and flexible manner. Remote Sensing will be used in creating images of how Jordan is seen from space, which will give the users more information and an overview about the study area. Satellite images could be converted into digital image maps, using digitizing procedures. The features viewed in the original scene could be studied by using different remotely sensed techniques. Landsat-7 (ETM+) and SPOT images were implemented, in order to extract the information needed for the topography of the region, land cover areas, boundaries, drainage patterns, road networks, man-used areas, vegetated areas and many other features in Al-Salt areas. The validity and the appropriateness of GIS and Remote Sensing techniques, particularly data fusion of images were evaluated in relation to visualization.
\end{abstract}

Key words: Geomatics science, GIS analysis, satellite images, data fusion, 3D analysis and relational database

\section{INTRODUCTION}

Among the advantages of GIS and Remote Sensing integration are to capture, accumulate, model, analyze and present spatial and descriptive data directly or indirectly from satellite image and from available maps. An electronic map makes a basic element of the GIS. The map functions in dialog mode providing access to non-cartographic Database (DB) accumulating reference, descriptive, statistic information connected with the object on the map. Non-cartographic data are visualized as tables, diagrams, graphs, images, including satellite images. Electronic maps are created in the instrumental GIS environment. Various sources like geographic maps, atlases, geographic descriptions, statistic and reference information, materials of local surveying compose the information basis for the electronic map. The interface should be designed taking into account the demands and abilities of the wide range of users. Therefore, implementing GIS and Remote Sensing techniques in order to produce relational data base for Al-salt area due to its rapid development was needful.

Location and access: Al-Salt region Study Area is located about $25 \mathrm{~km}$ north-west of Amman and could be approached from the capital via Sweileh-Salt highway (Fig. 1). The region covers an area of $655 \mathrm{~km}^{2}$.

Topography: Jordan River is a recent geomorphic feature; a well developed meandering system exists within its floodplain and the surrounding river terraces.

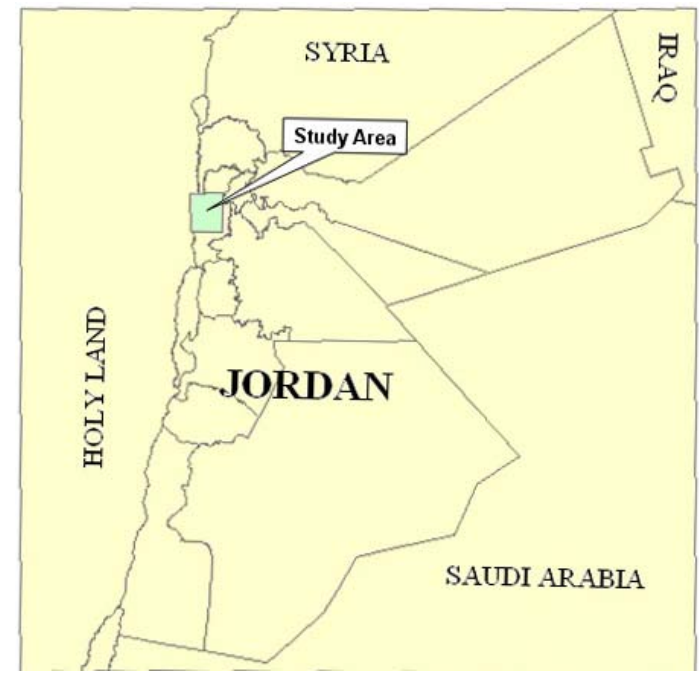

Fig. 1: Location of the study area

Corresponding Author: Eyad H.R. Fadda, Department of Surveying and Geomatics Engineering, Faculty of Engineering, Al-Balqa' Applied University, Al-Salt, 19117, Jordan Tel:/Fax: (+962 5 3530465) 
The lisan marl is heavily dissected by a dense drainage system to form typical badland topography, or what is locally termed katar. Such topography indicates the role of scattered rainfall and fluvial processes in shaping the weak marl formations in such arid areas. Along the base of the fault scarps, a series of alluvial fans developed by major Wadis (i.e., Wadi Kufrinja and the Zerqa River) and form a bajada plain. The general gradient of the bajada is less than $5^{\circ}$.

The second terrain is the fault scarps. This is up to $1000 \mathrm{~m}$ in elevation and overlooks the Jordan rift. Step faulting which initiated the rift has resulted in major fault scarps. The latter have been heavily modified by fluvial erosion during the fluvial periods of the Pleistocene-recent. In certain localities (i.e., arda road), the displaced down faulted blocks form pronounced foothills along the scarp line base. However, a complex system of slopes exists here (convex, concave and straight). The scarps are heavily dissected at present by a series of valleys ranging in depth between 1 and $3 \mathrm{~m}$. Some of them are terminated by minor alluvial fans.

The third terrain system comprises a hilly terrain exceeding $1000 \mathrm{~m}$ in elevation. Here the high rainfall, the folded strata and the presence of faulting have combined to form a hilly region of diversified scenery and innumerable outcrops of limestone, marl, shale, clays and sandstones.

Objectives: The main objectives of this study are:

- Building a relational database system that includes GIS layers and RS image maps and managing them

- Producing digital image maps for Jordan (Al-Salt)

- Evaluating the validity and the appropriateness of data fusion in relation to visualization

In order to reach the main objectives, we will pass through several stages each one has an objective. These secondary objectives are:

- Create a mosaic image for Jordan from SPOT image and Landsat-7 image

- Make band combinations

- Create different layers

- Create TIN for Al-Salt area

- Create terrain surfaces, slope, aspect, hill shade, view shade for Al-Salt area and perform 3D analysis

Methodology: SPOT satellite image, Landsat-7 image, topographic and geologic maps at scale 1:50,000 were employed in this study. Spectral enhancements and

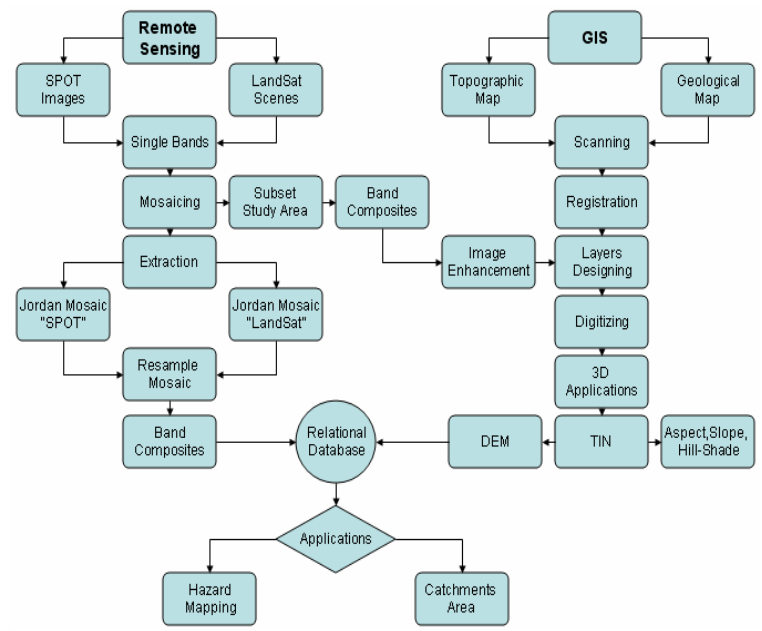

Fig. 2: Methodology flow-chart

textural analysis utilizing false color composite, highpass filter and directional edge enhancements were applied on the study area. New maps for Al-Salt area such as, drainage pattern, road network, vegetated areas, soil and faults were produced, thereafter, all the produced maps and their attributes have been stored as a relational GIS Database using Arc GIS software (Fig. 2).

\section{MATERIALS AND METHODS}

Images: Geo-referenced satellite images in the WGS84 UTM $36 \mathrm{~N}$ and $37 \mathrm{~N}$ coordinate system were used. The spatial resolution of these images is $10 \mathrm{~m}$ resolution for SPOT images captured in year 2002 and the Landsat-7 images at $25 \mathrm{~m}$ resolution taken in year 2000 .

GIS data: There are numerous definitions of GIS, none of which actually describe or explain it sufficiently. Sometimes we simply say Advanced Computer Mapping, but better definition is A computer-based technology and methodology for collecting, storing, managing, analyzing, modeling and presenting geographic data for a wide range of applications. A GIS is not simply a computer system for making maps, although it can create maps at different scales, in different projections and with different colors. A GIS is an analytical tool ${ }^{[2]}$.

The major advantage of a GIS is that it allows us to identify the spatial relationships between map features. A GIS does not store a map in any conventional sense: or does it store a particular image or view of a geographic area. Instead, a GIS stores the data from which you can draw a desired view to suit a particular 
purpose. GIS links spatial features with attributes about a particular location on a map. The information is stored as attributes of the graphically represented feature. For example, the centerline that represents a road on a map does not tell us much about the road except its location. To find out the road's width or pavement type, we must query the database.

Using the information stored in the database, we could create a display symbolizing the roads according to the type of information that needs to be shown. A GIS also uses the stored feature attributes to compute new information about map features, for example, to calculate the length of a particular road segment or to determine the total area of a particular soil type. In this study, there are two data sources for GIS: Hard Copy Maps and Existing GIS Layers.

Hard-copy maps: Maps can be defined as extremely accurate sketch which simulate the reality with three fundamentals special effects. The first is the map scale that applies the ratio between any distances on the map to the same distance on the ground, such as:

- $\quad$ Small map scale $>1: 250000$

- Medium map scale $>1: 100000$ and $<1: 250000$, used to determine the region boundaries

- $\quad$ Large map scale $>1: 25000$ and $<1: 100$ 000, used to determine the directions

- Details map scale $<1: 25000$, used to any civil applications

The second, it is the map projection which is defined as regular geometrical shape such as cylindrical, conical, that applied by equation to make transformation from the Earth coordinates (Three dimensions) to the map coordinates (Two dimensions), this transformation preserve the distance or shape or area, such as in the Universal Transverse Mercator (UTM).

The third is to determine the coordinates systems such as geographic coordinates (longitude, latitude and height) or Cartesian coordinates (X, Y and Z), notice that for coordinates systems the reference axis and origin point must be determined, for example to the terrestrial reference frame it is the World Geodetic System (WGS_1984). Therefore, it is important to collect the maps with the suitable projection system and scale. Maps have to cover the study area. The purpose of the maps collection is to determine the areas, the distances, to collect the Ground Control Points (GCPs) and to collect the satellite images covering the study area. So, maps collection is fundamental equipments for any surveying application. After that many processing, computations and analysis could be done to extract the purpose that you need from the maps ${ }^{[1]}$. Two maps were available in this study:

- Al-Salt Topographic Map at a scale of 1:50 000

- Al-Salt Geological Map at a scale of 1:50 000

Existing GIS layers: Layers are groups of features organized into an object called a Shapefile. In this study different vector layers were available from Department of Lands and Surveying (DLS). These layers are: buildings layer, road networks layer and Parcels layer.

\section{Software:}

ENVI 4.3: The Environment for visualizing images, is the most advanced, yet easy-to-use remote sensing software available. ENVI will transform the way you work with remote sensing data. ENVI software combines a complete image processing package with the most advanced spectral tools. ENVI also provides geometric correction, terrain analysis, radar analysis, raster and vector GIS capabilities, extensive support for images from a wide variety of sources and much more.

ENVI is a powerful tool for analyzing the content of hyper spectral images that is adaptive and easily modified for the desired workflow. A Governmentfunded independent assessment of a broad range of software tools indicated ENVI Software was the \#1 product for automated feature extraction and assisted target recognition. ENVI also earned Top Rating from NIMA Pathfinder 2002 Evaluation.

Project me: Project me is a type of programs that deals with transformations between projections, in order to convert the coordinates from one case to another and vice versa. This software was used to convert the coordinates from Geographic (WGS84) to WGS 1984 UTM zone 36.

ArcGIS (version 9.2): ArcGIS is the most important program for the GIS application exactly nowadays. The ArcGIS supports the virtual reality program, additionally with ArcScene and ArcGlobe we can consider it a type of virtual reality software (with some lack), the ArcGIS supports all type of data that is needed by Geomatics, for example all statistics data that must be joined with the features and stored in a database.

Processing: The collected data should be processed in order to get the desired results. The data type and the quality of the required results must be taken into consideration in the data processing. For example, the 


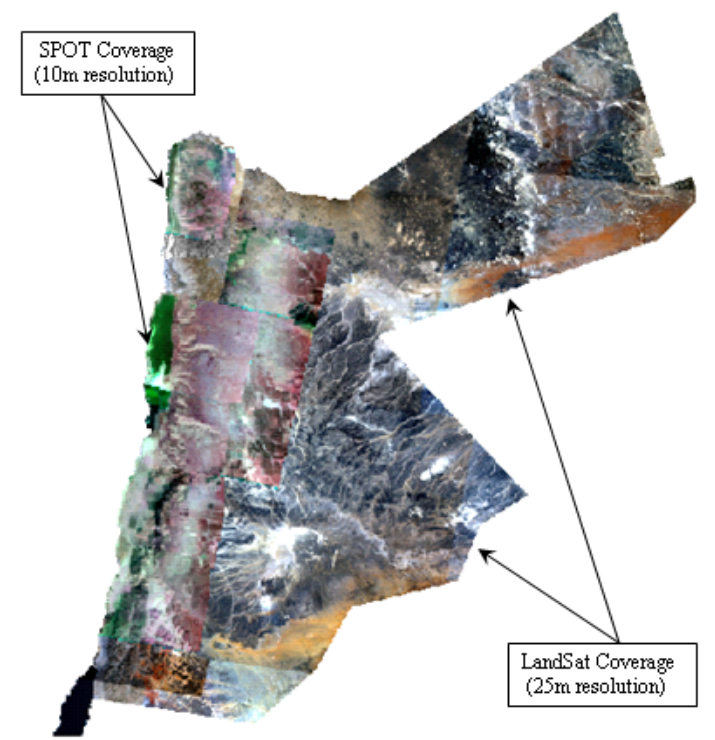

Fig. 3: Integrated mosaic for the fused image of SPOT and Landsat-7

digital image processing differs from GIS processing. Also, the processing of the hard-copy maps differs from that of the vector layers.

\section{Digital image processing:}

Data fusion: Advance technique in digital image processing, which is Data Fusion, was used to integrate between SPOT $(10 \mathrm{~m})$ resolution images and the Landsat-7 $(25 \mathrm{~m})$ resolution image. As a geometric integration on one hand, on the other hand we made integration between the 4 bands of SPOT images with the 3 bands of Landsat-7 image as a radiometric integration ${ }^{[5,6]}$ (Fig. 3).

Many works have recognized the benefit of merging multi-sensor and multi-resolution satellite data and numerous merging approaches, such as the IHS transform $^{[4]}$, PCA analysis ${ }^{[2]}$ and HPF method ${ }^{[7,8]}$.

On the other hand, depending on the application and the level of complexity of the observed scene, the different objects are better identified if high spectral resolution image is used. Hence, there is a desire to combine the high spatial and the high spectral resolutions with the aim of obtaining the most complete and accurate description of the observed scene ${ }^{[8]}$.

\section{RESULTS}

In general, data entry could be very time consuming, but it is the most important task of the GIS process. All the required GIS process for Al-Salt area were completed that including, data entering, scanning,

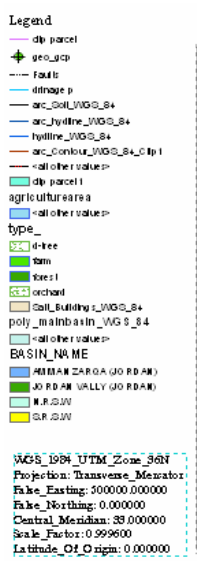

all layrs for the study area <AS SALT>

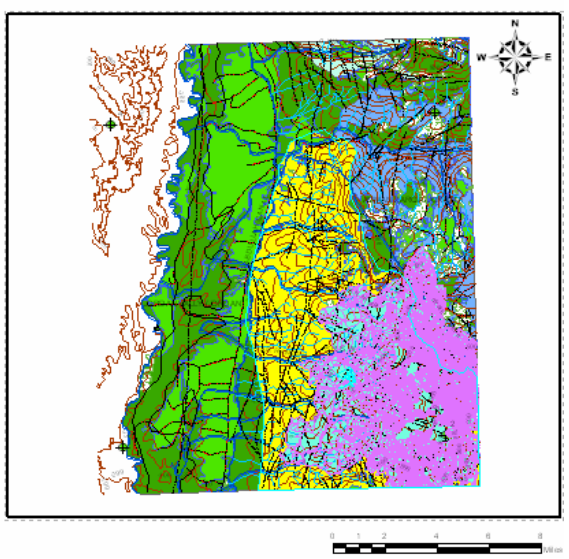

Fig. 4: All produced layers: road network, drainage pattern, contour lines, faults and many other terrestrial features

layers designing, digitizing, geo-referencing, projection, creating layouts and (3D) Applications using ArcGIS program.

Creating layouts for Al-Salt region: One of the primary objectives of this study is to create digital image maps for Jordan in general and for Al-Salt area particular. As a result of data entering, scanning, layers designing, digitizing, geo-referencing and projection, many layouts (maps) were produced for Al-Salt area, such as road network, drainage pattern, contour lines, faults and many other terrestrial features.

All produced layers and their attributes have been stored as relational GIS and RS database for Al-Salt area. Any layer can be produced as a single map for a thematic purpose. The entire produced layers were displayed for showing in Fig. 1. The legend shows the name of each layer (Fig. 4).

\section{DISCUSSION}

Data analysis is the process of interpreting data. This may range from simple exploratory data analysis, which involves simply looking at the data and describing what we see, to complex analysis such as modeling ${ }^{[6]}$. Standard GIS maps are in flat (twodimensional, 2D) format, but presentation of landscapes as three-dimensional (3D) views is very useful, both as communication from 2D to 3D involves geometric and trigonometric calculations of elevation points to make surface-fitting triangles called TIN (Triangular Irregular Networks). The triangles cover the region and represent the terrain so that a 3D perspective can be provided. The mathematics of the process is not important here. 


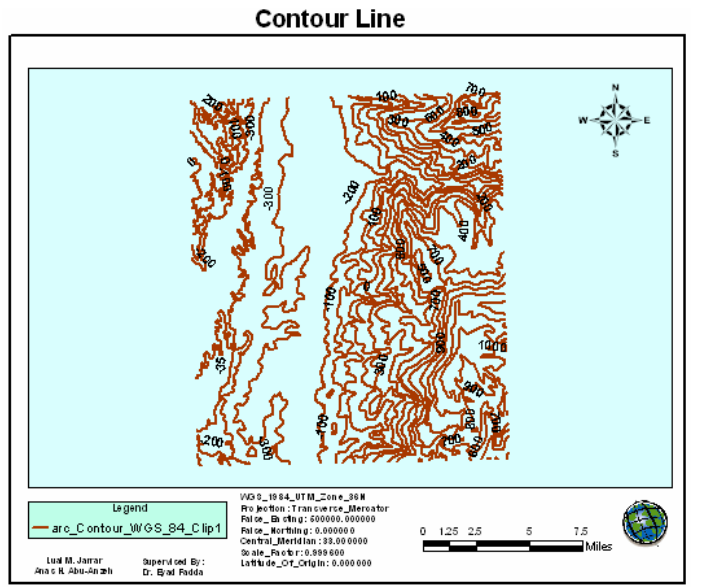

Fig. 5: Contour line layer

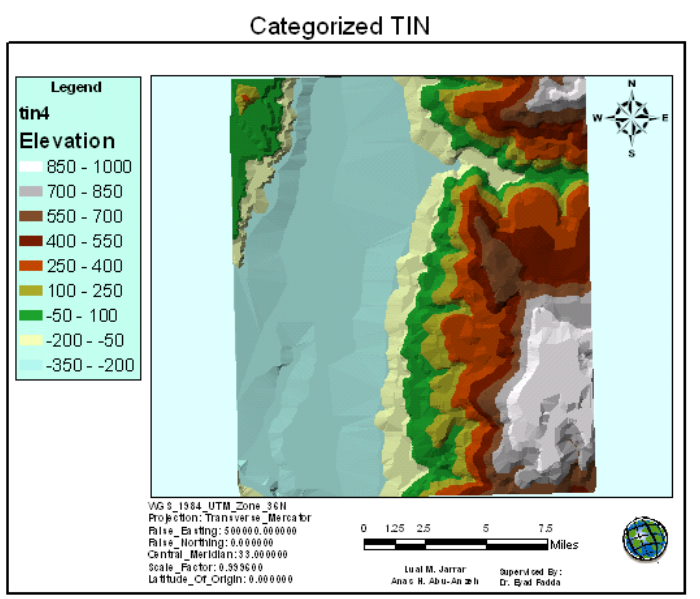

Fig. 6: Categorized TIN layer

But TINs are special data presentations that do not integrate with standard raster or vector data formats very well ${ }^{[9,10]}$. However, they are excellent visual description of the landscape. Based on Al-Salt Topographic Map, which has contour interval (20meter), we created contour layer, it contained a field for height of contour line, to take the base height in (3D) applications.

Create TIN: After digitizing the contour layer, the (3D ANALYST TOOLS) can be used to create TIN for AlSalt. Figure 5-8 show 3D analysis in the GIS environment.

Slope and aspect: Because TIN confirm to the surface, they can be used to calculate the degree of slope and aspect (direction characteristics) of the land. Slope is very important in many applications because it

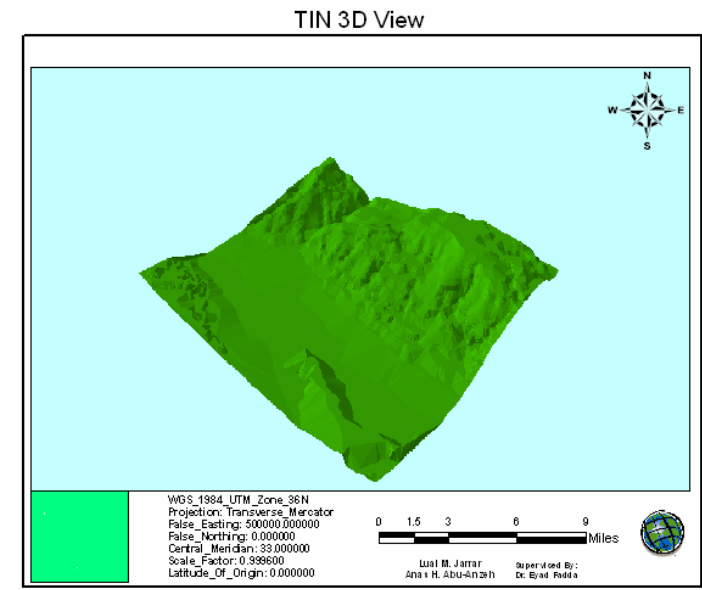

Fig. 7: TIN 3D View layer

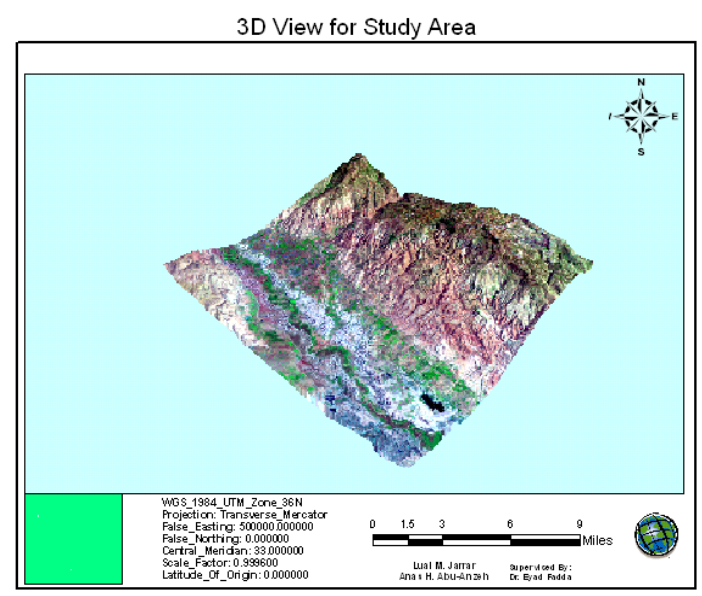

Fig. 8: Satellite image draped over 3D layer

determines steepness, indicates environmental conditions and influences the land cover, land use. Slope is one of the most critical information needs for resource managers and urban planners. After we made the tin, we used it to create TIN surface such as Aspect and Slope. Figure 9-10 show slope and aspect for study area.

Shaded relief views: Illumination applying 3D data creates shaded relief views. Shaded relief actually means that one part of the topography is illuminated and the other is in shade, with intermediate that parts in gray tones. To the eye, this gives an appearance of reality, making landscape interpretation easy and promoting further use of the data. Differences in topography can be very important spatial factors in many applications; shaded relief views are ideal data visualization presentation (Fig. 11-12). 


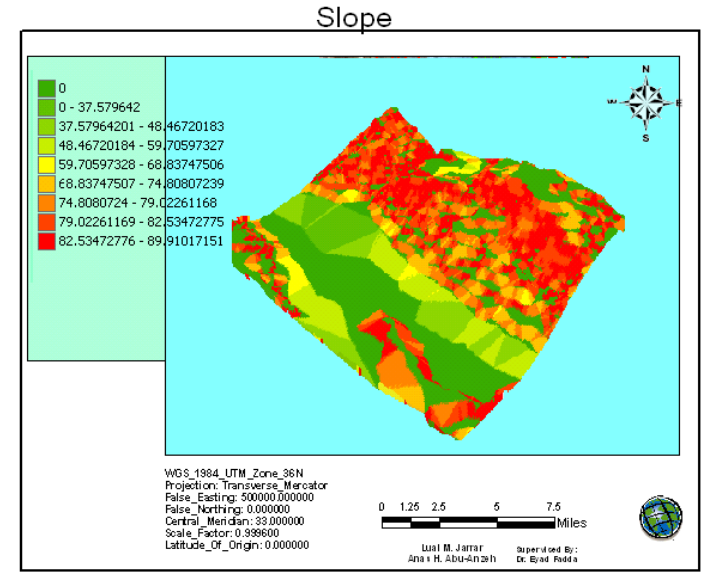

Fig. 9: Slope layer for the study area

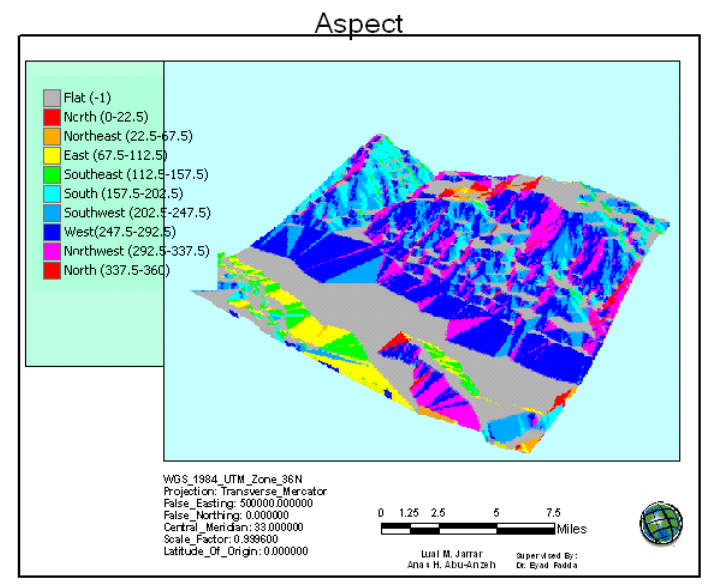

Fig. 10: Aspect layer for the study area

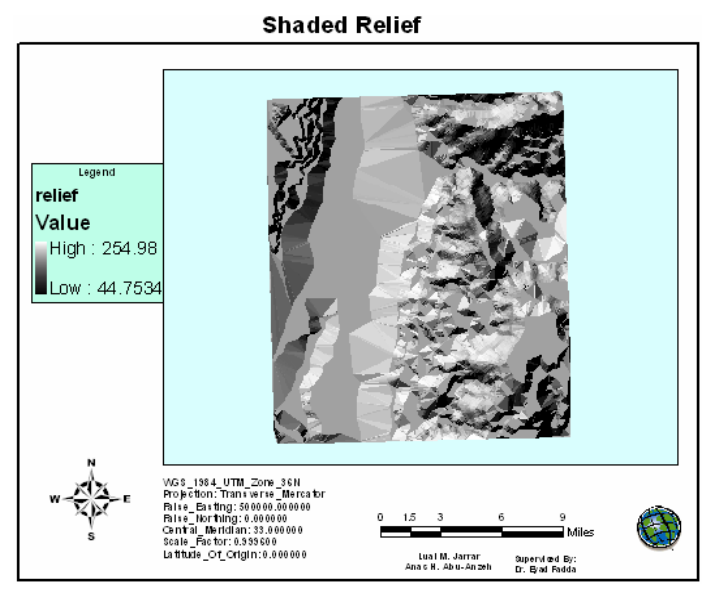

Fig. 11: Shaded relief layer for the study area

The efficiency of a database depends on how the data from different sources are managed, stored

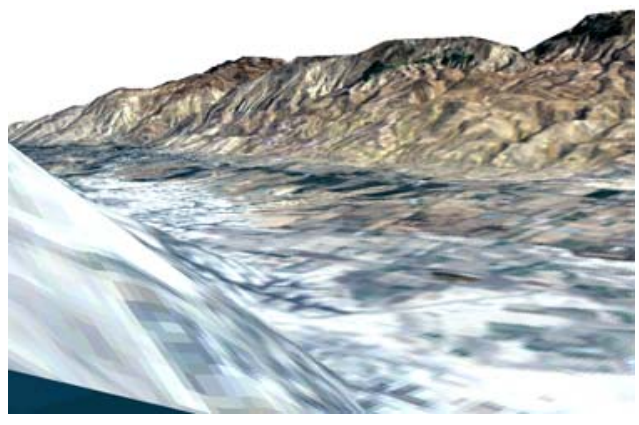

Fig. 12: Actual view for study area

andrelated with each other. The capability of future retrieval of the data, updating and analyzing, is where the power of a relational database exists.

\section{CONCLUSION}

Data Fusion as an advanced technique in digital image processing was used in order to integrate between SPOT $(10 \mathrm{~m})$ resolution images and the Landsat-7 $(25 \mathrm{~m})$ resolution image. This technique concerned in geometric integration on one hand and integration between the 4 bands of SPOT images with the 3 ( $R \quad G \quad$ B) bands of Landsat-7 image as a radiometric integration on the other hand.

The major advantage of a GIS is that it allows identifying the spatial relationships between map features. GIS does not store a map in any conventional sense: or does it store a particular image or view of a geographic area. Instead, a GIS stores the data from which you can draw a desired view to suit a particular purpose.

GIS was used to store feature attributes to compute new information about map features, for instant, to calculate the length of a particular road segment and to determine the total area of a particular soil type.

Digital image maps for Jordan and for Al-Salt area in particular, in addition to their attributes were produced. All the resultant images, digital maps, attributes, layouts have been stored as a relational GIS \& RS Database System for A-Salt area. The relational GIS \& RS Database System for Al-Salt area can be used for retrieval, updating, analyzing and modeling any required map or information.

\section{REFERENCES}

1. Bobrowsky, P.T., 2005. Geoenvironmental mapping-method. Theory and Practice, Swets and Zeitlinger BV. 2nd Edn. Taylor and Frances, ISBN: 9054104872. 
2. Chavez, P.S., S.C. Side and J.A. Anderson, 1991. Comparison of three different methods to merge multiresolution and multisepctral data landsat TM and SPOT panchromatic. Photogrammet. Eng. Remote Sens., 57: 295-303. http://www.fao.org/ agris/search/display.do?f=./1991/v1705/US911727 8.xml;US9117278.

3. Goodchild, M., R. Haining and S. Wise et al., 1992. Integrating GIS and spatial data analysis: Problems and possibilities. Int. J. Geograph. Inform. Sci., 6: 407-423. DOI: 10.1080/02693799208901923.

4. Haydn, R., G.W. Dalke, J. Henkel and J.E. Bare, 1982. Application of the IHS color transform to the processing of multisensor data and image enhancement. In: Proceedings of the International Symposium on Remote Sensing of Arid and SemiArid Lands, Cairo, Egypt, pp. 599-616. 607.

5. Jensen, J.R., 2007 Remote Sensing of the Environment: An Earth Resource Perspective. 2nd Ed., Upper Saddle River, NJ: Prentice Hall. http://www.cas.sc.edu/geog/rsbook/Exercises/Rse/i ndex.html.

6. Lillesand, T.M. and R.W. Kiefer, 2000. Remote Sensing and Image Interpretation. 4th Edn. Chichester: John Wiley and Sons, Inc., New York. ISBN: 0471255157.
7. Ranchin, T. and L. Wald, 2000. Fusion of high spatial images: The ARSIS concept and its implementation. Photogrammetric. Eng. Remote Sens., 66: 49-64. http://direct.bl.uk/bld/PlaceOrder. do?UIN $=072575192 \&$ ETOC $=$ RN\& from $=$ searchen gine.

8. Robinove, C.J., 1989. Principles of Logic and the Use of Digital Geographic Information System. In: Fundamental of Geographic Information Systems: A Compendium, Ripple, W.J. (Ed.). American Society for Photogrammetry and Mapping.

9. Sui, D.Z. and M. Ball, 2006. Geospatial Matters: Exploring the Implications of a Digital Earth. 1st Edition. San Francisco.CA. GeoTec Media.

10. Sui, D.Z., 1992. A fuzzy GIS modeling approach for urban land evaluation. Comput. Environ. Urban Syst., 16: 101-115. http://cat.inist.fr/?aModele $=$ afficheN\&cpsidt $=5374796$.

11. Wald, L., 2002. Data Fusion, Definitions and Architectures fusion of images of different spatial resolutions, $1^{\text {st }}$ edition. Les Presses. Paris, - Mines Paris. ISBN: 291176238X. 